\title{
Wound myiasis: the role of entodermoscopy*
}

\author{
João Renato Vianna Gontijo ${ }^{1}$, Flávia Vasques Bittencourt ${ }^{2}$
}

DOI: http://dx.doi.org/10.1590/abd1806-4841.20188043

\begin{abstract}
Although wound or traumatic myiasis is common in tropical countries, only recently cases associated with underlying dermatoses, such as seborrheic dermatitis and psoriasis, have been reported. We describe a patient with seborrheic dermatitis and an ulcerated lesion on the scalp, in which the dermatological examination with the aid of dermoscopy allowed the identification of larvae (maggots) compatible with infestation by Cochliomyia hominivorax. Treatment was performed with oral and topical ivermectin, followed by manual extraction of the larvae.
\end{abstract}

Keywords: Dermoscopy; Larva; Myiasis; Wound infection; Wounds and injuries

A 27-year-old male patient, with mental disability due to congenital toxoplasmosis, presented with a painful ulcer on the scalp that had been present for two weeks after vacationing in a rural area in Brazil (Figure 1). Physical examination also revealed erythema and desquamation on the scalp, suggestive of seborrheic dermatitis, and excoriated areas. Dermoscopy allowed the visualization of multiple live larvae in the ulcer, with pigmented tracheal tubes, respiratory spiracles and bands of spines encircling the anterior portion of each body segment (Figure 2 and Video 1). Correlation of clinical, epidemiological, and entomological findings was consistent with the diagnosis of wound (traumatic) myiasis. Treatment with oral ivermectin $200 \mu \mathrm{g} / \mathrm{kg}$ in a single dose was administered, followed by occlusion with $10 \%$ ivermectin ointment, with no improvement. Due to the presence of live larvae, mechanical extraction of the parasite was then performed, removing 27 live maggots from the lesion (Figure 3).
Myiasis is a parasitic infestation of humans and vertebrates by larvae of insects of the order Diptera (true flies). ${ }^{1}$ Its cutaneous presentation is divided into furuncular, migratory and wound (traumatic), according to the clinical findings and the species of the larva. ${ }^{1,2}$

In the New World, the vast majority of wound myiasis cases are caused by larvae of flies of the Calliphoridae family, which includes Cochliomyia hominivorax, the most prevalent species in Brazil. ${ }^{2}$ Its characteristic clinical finding is the presence of multiple larvae in the lesion, as described in this report. Morphologically, pigmented tracheal tubes and anterior respiratory spiracles differentiate the larvae of Cochliomyia hominivorax from larvae of other species. ${ }^{3}$ Predisposing factors include open wounds, poor hygiene and social conditions, very young or advanced age, psychiatric disorders and intellectual disability. The absence of a previous wound or ulcer in clinical history does not rule out the diagnosis, since cases of wound myiasis have been described in patients with dermatoses

\footnotetext{
Received 31 December 2017.

Accepted 15 March 2018.

* Work conducted at a private clinic, Belo Horizonte (MG), Brazil.

Financial support: None.

Conflict of interest: None.

Department of Dermatology, Oregon Health and Science University, Portland (OR), United States of America.

2 Dermatology Unit, Hospital das Clinicas, Universidade Federal de Minas Gerais, Belo Horizonte (MG), Brazil.
}

MAILING AddRess:

João Renato Vianna Gontijo

E-mail: joaorenato20@hotmail.com 


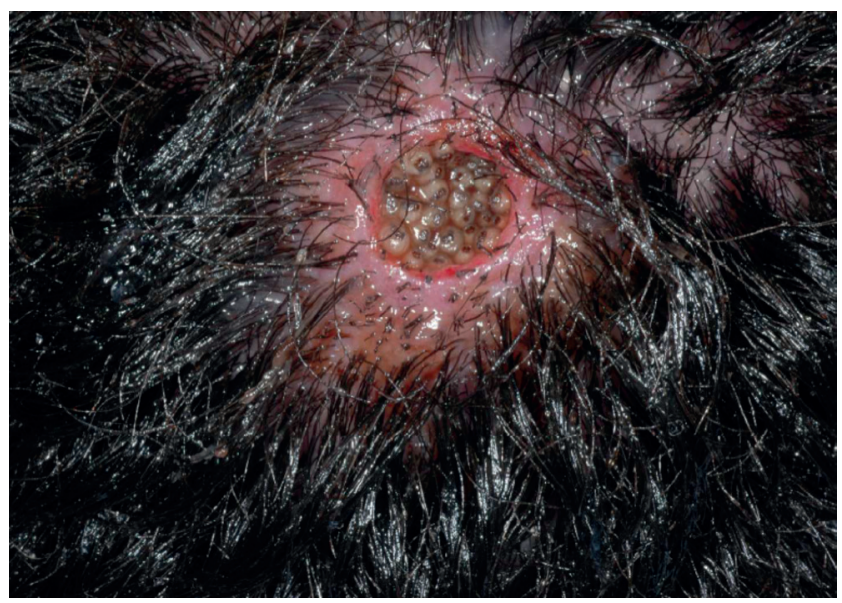

FIGURE 1: Well-circumscribed round ulcer with multiple larvae

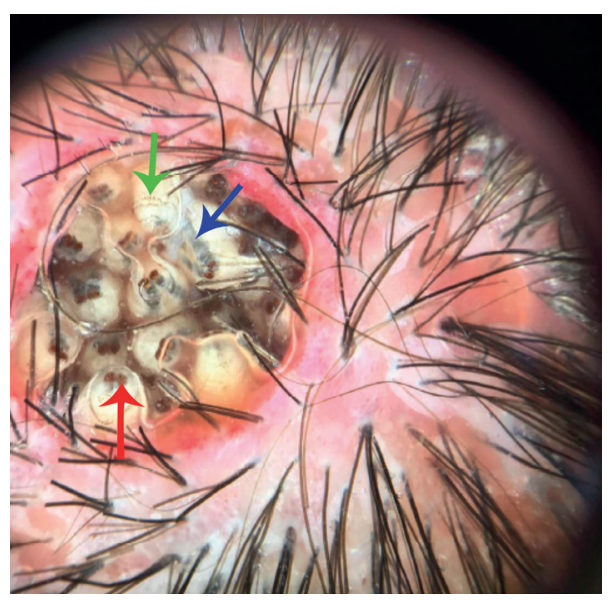

FIGURE 2: Numerous yellowish-white larvae, with multiple brown dotted rings (green arrow), tracheal tube (blue arrow) and respiratory spiracle (red arrow). Erythema and perifollicular scaling on the scalp can be seen in the periphery

on the scalp, such as seborrheic dermatitis and psoriasis. ${ }^{4,5}$ In such instances, the term traumatic myiasis is preferred to wound myiasis. Manipulation of the skin lesions in such dermatoses is likely to act as a predisposing factor. In our patient, both mental disability and seborrheic dermatitis could well have contributed not only to the onset of the disease, but also to its exuberant presentation.

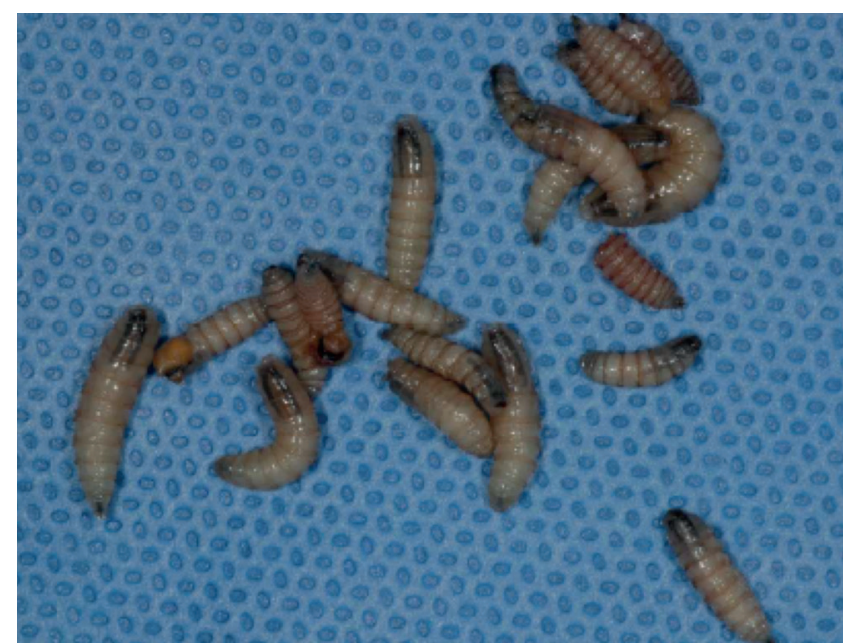

Figure 3: Macroscopic appearance of Cochliomyia hominivorax larvae after extraction

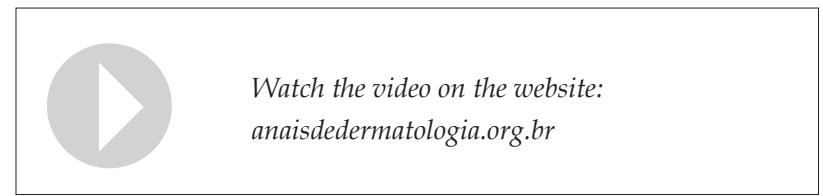

VIDEO 1: Multiple moving yellowish-white larvae under dermoscopy

Dermoscopy has been increasingly used as an auxiliary diagnostic method in dermatology, including inflammatory, infectious and parasitic diseases. ${ }^{6}$ Coupled with the clinical history, dermoscopy can avoid unnecessary surgical procedures, especially in cases of furuncular myiasis, whose differential diagnosis can be challenging. ${ }^{7}$ There have been few reports on dermoscopic findings, yet these findings can contribute to the identification of the parasite species (entodermoscopy) through the visualization of characteristic structures, such as pigmented tracheal tubes and anterior respiratory spiracles., 6

Treatment can be performed by lesion occlusion, manual extraction of the larvae, and larvicide. ${ }^{1}$ Ivermectin $200 \mu \mathrm{g} / \mathrm{kg}$ in a single dose, either alone or associated with topical ivermectin (1-10\%), is considered effective and safe, and can be repeated if necessary. ${ }^{8}$ 


\section{REFERENCES}

1. McGraw TA, Turiansky GW. Cutaneous myiasis. J Am Acad Dermatol. 2008;58:907-26.

2. Robbins K, Khachemoune A. Cutaneous myiasis: a review of the common types of myiasis. Int J Dermatol. 2010;49:1092-8.

3. Books.scielo [Internet]. Silva BF. Miíases. In: Amarante AFT, Silva BF, Ragozo AMA editores. Os parasitas de ovinos. São Paulo: Editora UNESP; 2014. p. 206-251. E-book [cited 2017 Dec 1]. Available from: http://books.scielo.org

4. Calderón HP, Rojas EC, Apt BW, Castillo OD. Miasis cutánea por Cochliomyia hominivorax asociada a dermatitis seborreica: Case report. Rev Med Chil. 2017:145:250-4
5. Mariwalla K, Langhan M, Welch KA, Kaplan DH. Cutaneous myiasis associated with scalp psoriasis. J Am Acad Dermatol. 2007;57:S51-2.

6. Calderón-Castrat X, Idrogo-Bustamante JL, Peceros-Escalante J, Ballona R Wound myiasis caused by Cochliomyia hominivorax: the role of entodermoscopy. Int J Dermatol. 2017;56:330-2.

7. Bakos RM, Bakos L. Dermoscopic diagnosis of furuncular myiasis. Arch Dermatol. 2007;143:123-4.

8. Dourmishev AL, Dourmishev LA, Schwartz RA. Ivermectin: pharmacology and application in dermatology. Int J Dermatol. 2005;44:981-8.

Approval of the final version of the manuscript, Design and planning of the study, Preparation and writing of the manuscript, Collecting, analysis and interpretation of data, Critical review of the literature, Critical review of the manuscript

Flávia Vasques Bittencourt $\quad$ (iD) ORCID 0000-0003-0087-6806

Approval of the final version of the manuscript, Preparation and writing of the manuscript, Effective participation in research orientation, Critical review of the literature, Critical review of the manuscript

How to cite this article: Gontijo JRV, Bittencourt FV. Wound myiasis: the role of entodermoscopy. An Bras Dermatol. 2018;93(5):746-8. 